\title{
BUILDING SOCIAL? MORE LIKE DESIGNING TO AFFORD CONTESTATION
}

\author{
Marcus Willcocks
}

\begin{abstract}
This paper discusses some of the urban impossibilities of 'building social', and reveals insights gathered through efforts to afford productive spatial contestation and agonistic practices. Three design led case studies are discussed. The first emerging with Spain's national institute for sport across 30 sites in Barcelona, the second located at the 'undercroft' of London's Southbank Centre and the third, operating between the social and physical spaces occupied by the Graffiti Dialogues Network, hosted at the University of the Arts London. All exemplify arguments that spatial democracy and 'improvement' is tricky. Also that design-led practice and research activities can aid socio-spatial conflict mitigation, by finding, and by designing-in, new spatial opportunities for agonistic contestation.
\end{abstract}

\section{INTRODUCTION}

Charles Montgomery assures us that 'Built spaces can make us happy' (2013) and Robert Sampson presents evidence that relation-focused neighbourhood organisation and design can make us safer and more socially efficacious (2012). Their inputs follow in a line of 'social turns' discussed for example, by Latour (1992) in terms of sciences, Bishop (2006) in terms of collaborative fine arts. Since then however, a wider creative turn appears to have emerged in urban realms, among which practice-led disciplines, activists, labs, designers, researchers, policy makers, and groups of doers, are variously attempting to improve or recalibrate (e.g. Ballaz, September 2015) our designed and built environments, for socially constructive ends.

This paper embraces Sampson and Montgomery's visions for urban improvement, yet contends that improving social scenarios in designed and built contexts is invariably wicked. That is to say 'wicked' in the sense described between Churchman (1967), Rittel and Webber (1984) and more recently Gamman and Thorpe (2012), that complex societal problems present multiple and conflicting desirable outcomes. These are challenges that host no single problem owner and no single possible resolution. This paper will elaborate on such scenarios by examining and drawing on learning from three case studies. Each involves design-led research activities, and support arguments for designing-in opportunities for agonistic contestation - programmed within place making or management processes, but also un-programmed or informal forms of play, appropriation and creative practice in city spaces. My discussion is stimulated in part by significant questions raised through the 'Designed to Improve?' workshop hosted in Hamburg in $2014^{1}$. Ultimately I set out to interrogate further some of the impossibilities of 'building social' $^{2}$ and to reveal insights gathered via three recent practice-led activities. The first emerged with Spain's national institute for sport across 30 sites in Barcelona, the second at the 'Undercroft' of London's Southbank Centre and the third, located between the social and physical spaces occupied by the Graffiti Dialogues Network, hosted at the University of the Arts London.

I use these examples of primary action research (Reason and Bradbury, 2001) to contend that sometimes difficult contestations played-out with and through informal urban 
practice(s) are equally vital to positively evolving or improving ${ }^{3}$ urban social challenges as developing actual buildings, streets and cityscapes. The design task here locates itself among scenarios with discordant requirements of communities involved and affected, which present wicked challenges that host no one discernible problem owner, nor a possible single resolution, as Churchman (1967) and Rittel and Webber (1984) might describe. Collaborative practices of place-making and place-sustaining are thus confronted not just to design objects or built solutions but to try and deliver 'agonistic opportunities'. Such opportunities have been described by Mouffe (1999) and Young (1990) in terms of political democracy, by Amin (2008), Pløger (2004), and Brand and Gaffikin (2007) in terms of social geography and urban planning, and later DiSalvo (2012) in terms of 'adversarial design'. These bring us to urban forms of agonism where the exchange is not only verbal or written but also emerges through diverse urban actions and spatial engagements. My review that follows considers why 'improvement' through design is tricky (Fisher and Gamman, 2014; Fisher, 2012), and why achievement of 'better' can be intended but also unintended. We see that spatial contestations can be awkward, generative and imaginative.

\section{CASE 1: Space, Sport and Social Inclusion}

The project 'Urban Public Spaces and Sport as Generators of Social Networks in Large Cities' emerged building on earlier work (Puig et al. 2006) with a team at the Laboratory for Social Research of Catalonia, part of INEFC ${ }^{4}$, Catalan institute for sport and physical education. The initiative set out to interrogate, through 30 spaces across Barcelona, the role of sporting activities in promoting urban social connections and urban wellbeing. The Barcelona Strategic Plan for Sport sought to 'promote the utilisation of public space for the practice of sport and physical exercise as a social generator for the city' (Puig et al., 2006).

The project team worked at learning from, and subsequently at exposing or nudging new opportunities related to sporting activities and their variable relations with other users and administrators of the spaces they occupy. Inputs came partly from social scientists but importantly from the sporting practitioners and local citizens who engaged, too. This action research also took place with urban planners, designers (including myself as codesigner focussing on social and spatial practices), and city administrators. In short, some municipal provisions were not achieving this (fig. 1) whilst other informal designs or less programmed appropriations were reaching much closer to this ambition (fig. 2). 


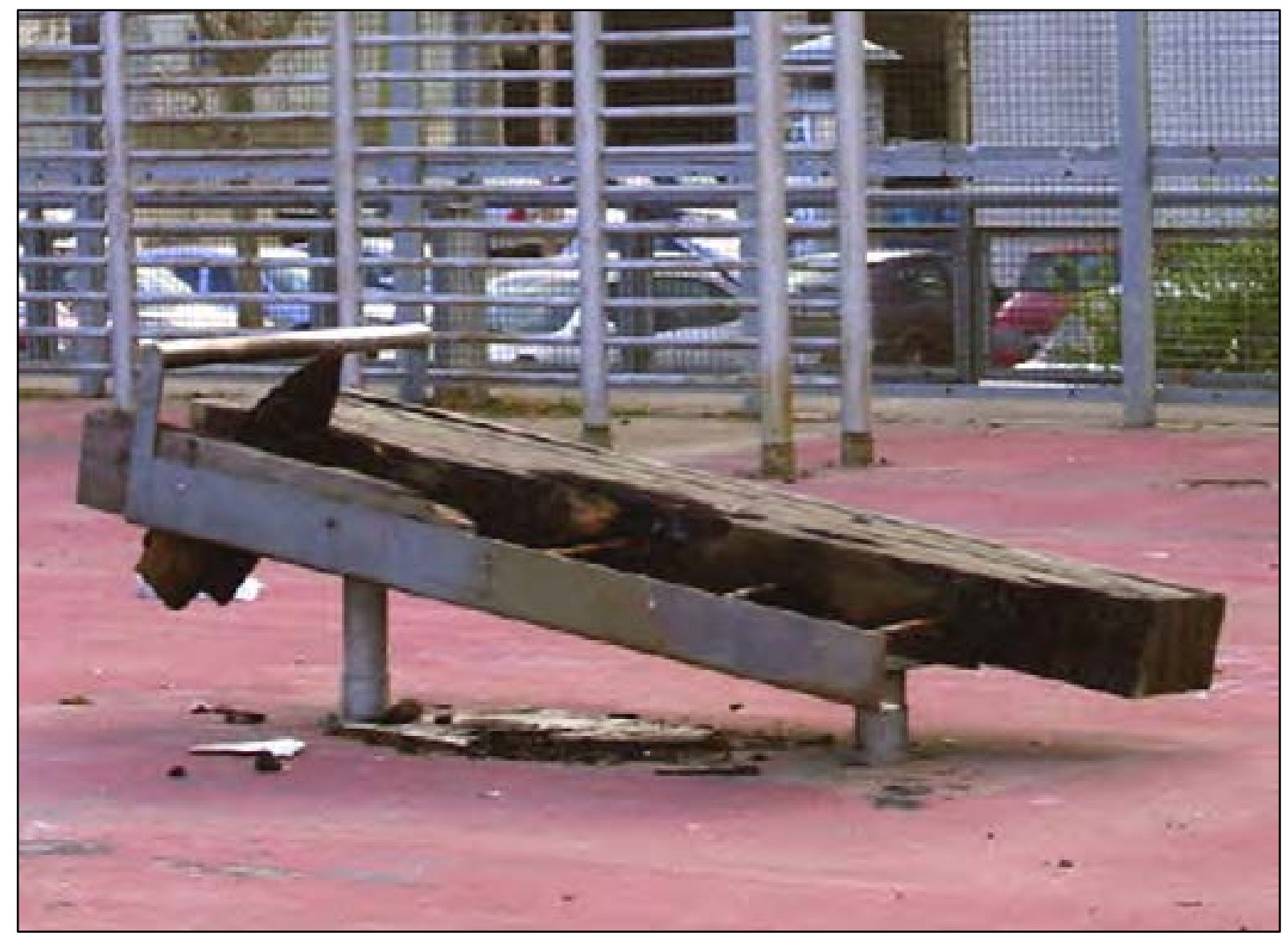

Fig. 1. A high-spec municipal (formal) sporting provision at one of 30 sites studied in Barcelona. Through multiple visits we learned the the facilities did not afford spatial uses that served or suited the local residents well. Consequently, the gym lay unused, became vandalised and frankly could not be described as a positive host to social activity. Photo: Marcus Willcocks. 


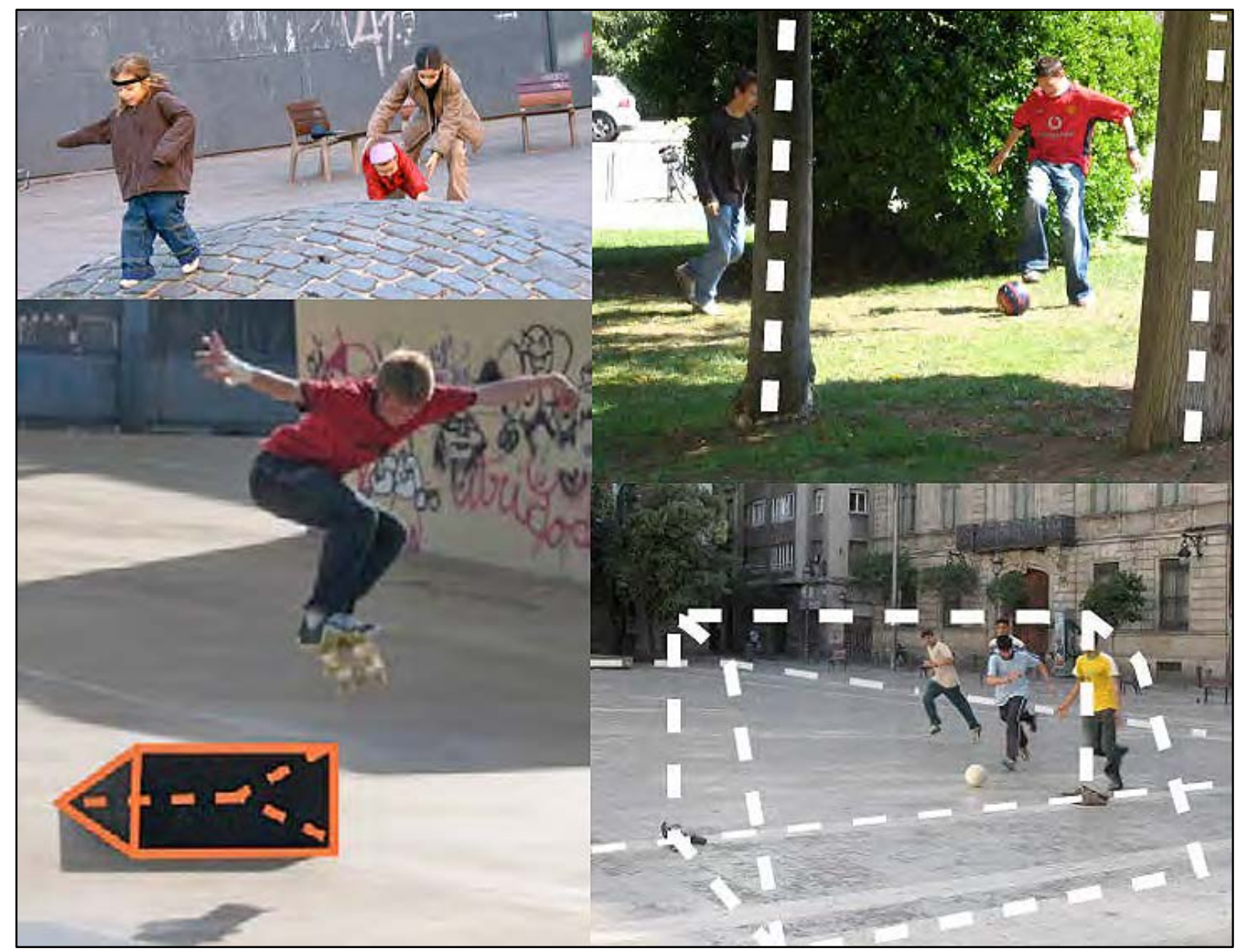

Fig. 2. Appropriated (informal) sporting and physical activity, bringing new designs on shared city spaces. Photos: Marcus Willcocks.

The 30 different sites studied hosted both informal (socially organised) and some formal (institutionally facilitated) sporting communities, as well as all the residential and nonsporting users of the same spaces - presenting hugely differing demands and interpretations on singular spaces. The disparate communities-of-interest did not easily afford the social ties ${ }^{5}$, cohesion or willingness-on-behalf-of-others that Sampson, Raudenbush and Earls (1997, 918) and Montgomery (2013) discuss. The diverse individual and group activities certainly 'generated' some socio-spatial cohesion within interest-networks. However, in these publically shared terrains, cohesion among a given peer-network did not mitigate possible discord where they crossed paths with other publics.

Most of the tensions identified were conflicts of interest (as opposed to conflicts of physical or verbal harm) between people. For example, the threat of a collision between skateboarders and pedestrians, or the perceived invasion of a new group establishing regular fixtures of a 'modern' sport on a spot otherwise used for 'traditional' 6 sporting games by lifelong locals. Such struggles were frequently territorial and based on the culturally-informed rules and codes which users read (interpreted) into a given space and its layout (Willcocks, 2008, 2, 12). It proved hard, for example, for a group of predominantly native senior petanc players to accept another group wanting to regularly play volley ball on one of the sites, where the ground-shape and layout worked so well for petanc. The spot could have been adapted and loosely programmed to the exclusion of neither interest but to the petanc players, the visual codes in place were clearly defined. To the eyes of the volley players however, the codes transmitted by the space suited their activity and they could not understand why the petanc players did not comprehend this new claim on the site, which in principle might have been equal. The stand-off 
between groups resulted more from the differing principles of interest than from the small handful of differences in physical demands that they each brought to the space.

Some contestations emerged as clashes over material provision and interpretation more than a clash between interests. These included formally-provided facilities being underused, or purposely abused (damaged) (e.g. fig. 1). In parallel less-formally defined spaces being 're-envisioned'. These, mostly unauthorised, interventions ranged from pegs affixed to street furniture to hang petanc equipment or belongings, to site-welded plaza modifications for skaters, through to demarcation of outdoor kitchen-spots and stepped-seating hewn from grassy banks, both for 'ecuavoley'7 groups to set up base for the day.

Iris Marion Young (1990) suggests that a city and its dwellers should recognise that their ways of being as public are not the only ways of being together as publics. To this end, the reinterpreted spaces observed in Barcelona that were not formally designated, or those that were flexible enough to be reworked, typically proved to be the contexts where this recognition between diverse dwellers could occur. Those sites acted as better hosts to accommodate wider ranges of practices and publics, without agonism escalating to antagonism. In contrast, some of the formal urban sporting provisions proved to be sites of greater damage, or exclusion or abandonment.

One of the recommendations from this project was to consider in terms of designed space, how spatial 'codes' are variously interpreted and reappropriated between distinct interest-groups (discussed by Willcocks, 2008). Robert Sampson articulates that 'collective efficacy' is the process of activating social ties among local networks, in order to achieve collective goals, and that this is achieved when there is 'social cohesion among neighbours combined with their willingness to intervene on behalf of the common good' (Sampson, Raudenbush and Earls, 1997, 918). While the spaces studied hosted limited collective efficacy across the groups encountered, the starting point for reaching such cohesive ties as Sampson observes, is here in the affordance of on-going contestations through practice. Over time, some of these contestations increased familiarity whilst permitting difference between dissimilar networks. Among the 30 sites, the more agonistic spatial scenarios encountered, where different publics brought different visions to a single space, were certainly the sites showing most opportunity for diverse social groups to engage through their respective practices. The sporting practitioners had been pioneers, as appropriators in these spatial conversations and contestations, by designing-in their own responses. The next step for creators and managers of sites intended to serve as 'socially-generative' (Puig et al. 2006) is, to design to accommodate such contestations at wider scales from the outset - in this case to help promote varied socio-physical activity in urban contexts, without ending up with antagonistic, unusable or unwanted shared spaces.

\section{CASE 2: Southbank Undercroft}

In Spring 2013 the Southbank Centre advised that they needed to move the activities from the Southbank Undercroft, located below London's Queen Elizabeth Hall - the space also known fondly as South Bank among skateboarders, bmxers and graffitists and street artists. Southbank Centre were proposing a large re-development, the 'Festival Wing.' They hoped to open up cultural opportunities to a wider social demographic, promising $50 \%$ free events and activities. However, diminished public arts and culture funding meant the proposal was dependent on a large loan which, it was suggested could only be secured by rental income from the conversion of the Undercroft into high-value commercial spaces. The skate, bmx and 'urban art' activities would have to relocate to a spot approximately 100 metres away.

This however omits that the Undercroft space had also been the cultural and for some spiritual home of UK skateboarding for over four decades (Borden, 2001, Schafran, 2014 
and Mayer, 2013). The site - also known as London's Skate Spot, London's Legal-Wall or just South Bank, depending who you ask - was already an exemplar case of multiple forms of social life being spatially organised and established, as Sampson (2012) discusses.

The Southbank Centre approached the Socially Responsive Design and Innovation unit at Central Saint Martins (CSM) including myself, to design and coordinate an independent and participative set of engagements about the new proposals. The request was first to increase established contact with existing Undercroft users, and alert them to proposed Festival Wing developments; and secondly to invite them to become involved in the process of defining some elements of the new proposals ${ }^{8}$.

The CSM team advocated a series of accessible, responsive and collaborative design (co-design) activities, to be realised with people who used or associated themselves with the Undercroft site. An iterative, transdisciplinary approach to 'open innovation' (Gamman and Thorpe, 2011) was developed, to allow democratic and fruitful engagements to occur.

This included open workshops of varied scales and formats, interest-themed working groups with nominated representatives, openly streamed working spaces, on-site design engagement and ideation activities, and more (fig. 3). These and other methods served as design 'devices' (Manzini \& Rizzo, 2011), to enable as much equity as possible, between the Southbank Centre as 'dutyholders', and the skaters, bmxers, graffiti writers (and associated physical and virtual social networks) and other publics as 'stakeholders'. Gamman and Thorpe report our thinking behind this co-design type approach:

'We have found it useful to consider the metaphorical 'space' of a collaborative design project as an agonistic space [...] in an attempt to grant equity of agency to actors and to enable contribution to the co-design process [whereby participants can get on-board] the co-design journey, toward collectively articulated destinations' (Gamman and Thorpe, 2012).

The process started well, in addressing topics arising between the multiple desirable outcomes at hand. We were quickly able to contact individuals and networks of actors who participated in feeding back, in-person and online (fig. 3). Representative contributors were nominated and working groups activated, starting to co-design responses and ideas (fig. 4) to be prototyped in consecutive stages. 


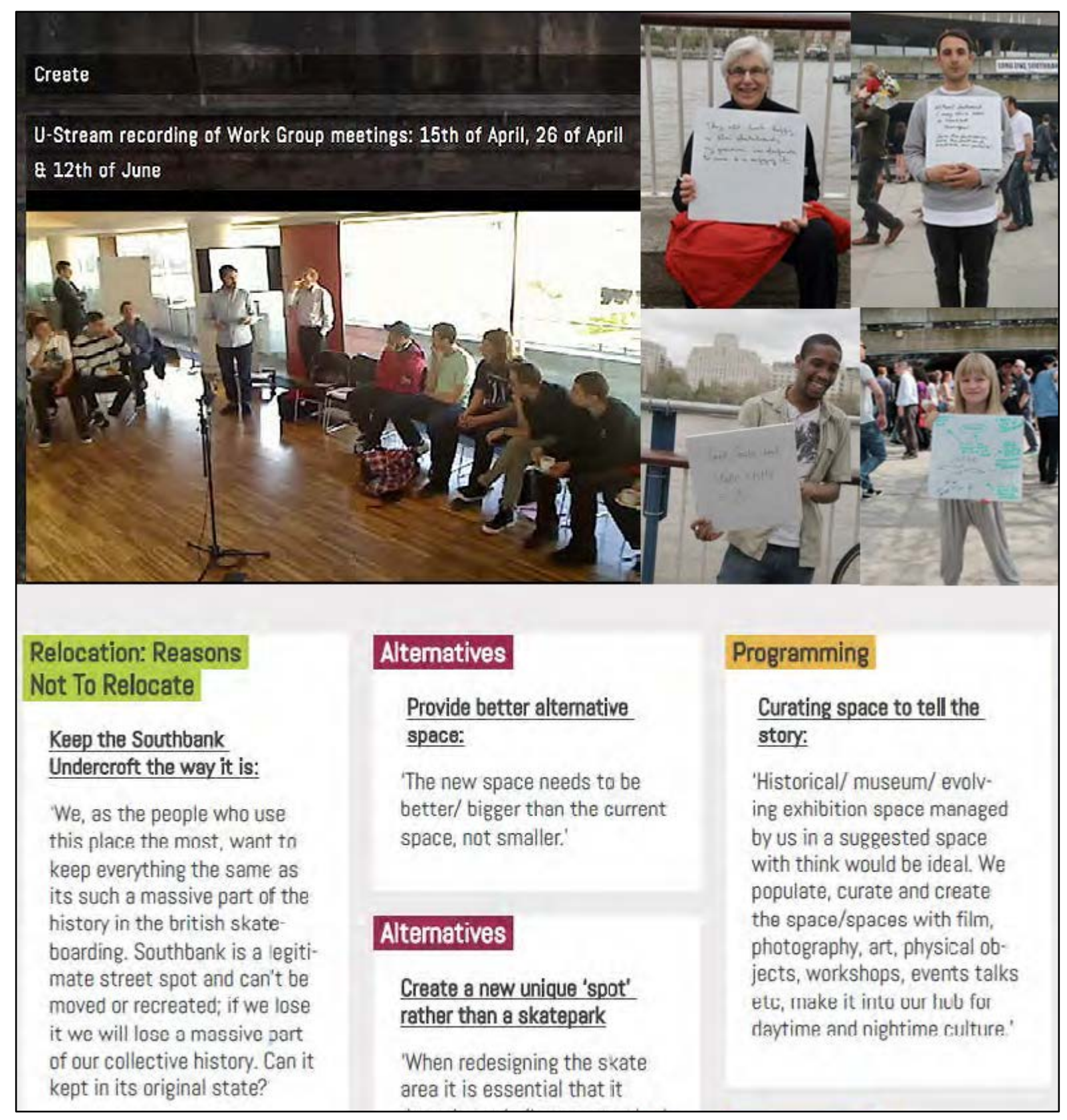

Fig. 3. Involving representative working groups and individuals in a number of design-led processes, addressing multiple desirable outcomes. Image: Southbank Undercroft codesign work groups and Socially Responsive Design \& Innovation, Central Saint Martins.

The collaborative progression of proposals being discussed was most challenged when members of both stakeholder and dutyholder groups started to antagonistically disregard ideas or ambitions of others, to the extent that they refused to consider further collaboration to explore alternative possibilities. The result was a stand-off between Southbank Centre's 'Festival Wing' scheme, set against an energised group of Undercroft regulars and growing social networks, mostly represented by the 'Long Live Southbank' (LLSB) campaign ${ }^{9}$. Ex-Undercroft-skater John Crace described to the Guardian

'The sport's history [at the Undercroft] lies in the way skaters have adapted to their environment - but a shopping arcade [...] will be the kiss of death for a modern landmark in urban youth culture. A landscape that has been the backdrop to the entire history of a culture that has gone from minority to 
mainstream in less than 40 years is surely something worth preserving.' (Crace, 29 July, 2013)

Over 60,000 supporters agreed by signing LLSB's petition, and in February 2014, Mayor Boris Johnson enforced the retention of the Undercroft space as a 'piece of living architectural history'. Critics retorted that the significant public unified as LLSB, in fact represents only a single-issue (skate-culture) among many single-issues and publics affected. Sarah Sands writing for the Evening Standard observed that

'City Hall was spooked by the [signatures] in favour of the skaters. [...] The skater boys are media-savvy, have access to good lawyers and know their commercial worth. They are, in fact, the new Establishment. [...] The skaters should be transparent about their commercial clout. It is the poor homeless violinists who have no powerful backers.' $(2014,15)$

As the struggle became more political and publicised, those voices who had been able to contribute but did not comfortably fit 'for' or 'against' hegemonies became subdued (a phenomenon also observed by Cavuşoğlu and Strutz, 2014). Willingness to experiment or contend with alternative possibilities began to wane. The situation seemingly revealed some limitations of the organised capacities of 'strife', which Pløger (2004) discusses for planning and built environment practices. He refers to the capacities for working with 'the ongoing dispute about words, meaning, discourses, visions, or "the good life" as a necessity, 'if the goal is to empower citizens and enhance their capabilities to participate ...' $(2004,73)$. The case of Southbank Undercroft showed that for agonistic contestation to achieve collectively generative responses, adversaries need to remain willing to prototype. That involves prototyping ideas through diverse practices, prototyping new balances of power in material as well as political senses, and prototyping change in agile rather than fixed ways. These are all possibilities within design processes ${ }^{10}$ which were not given opportunity to develop fully in this setting, because a 'them' and 'us' press and social media-fuelled discourse emerged. Instead, what took place became more reflective of Pløger's later analysis:

'The planning system [of which the Southbank Centre was subject] favours the rational and legal solutions to antagonism above agonism, because public planning is viewed as a conflict between 'enemies' and not 'adversaries'. Conflicts are seen as something that need 'permanent' solutions [...] and not something to be disputed about.' $(2004,86)$

Pløger certainly depicts well something of the 'wicked' scenarios at hand. Susan Fainstein adds to this understanding. She highlights that the equity achieved through agonistic approaches ultimately 'depends on the content of [the] demands' $(2014,13)$. The content of conflicting demands being made on the Undercroft could initially be addressed through workable co-design and socially responsive processes (Gamman \& Thorpe, 2011). In the wider picture, more traditional political (single-issue-driven) and press-fuelled actions emerged as powerful new content that ultimately operated to pitch one fixed vision for that site, against another fixed vision. Evidently, the clearest glimpses towards equitably-negotiated resolutions came before that: when multiple visions had chances to bring their respective lenses of practice to forms of generative and creative thinking (design thinking). This included moments when adversaries began to conceive how disparate wishes on that one environment might somehow intertwine or juxtapose. 


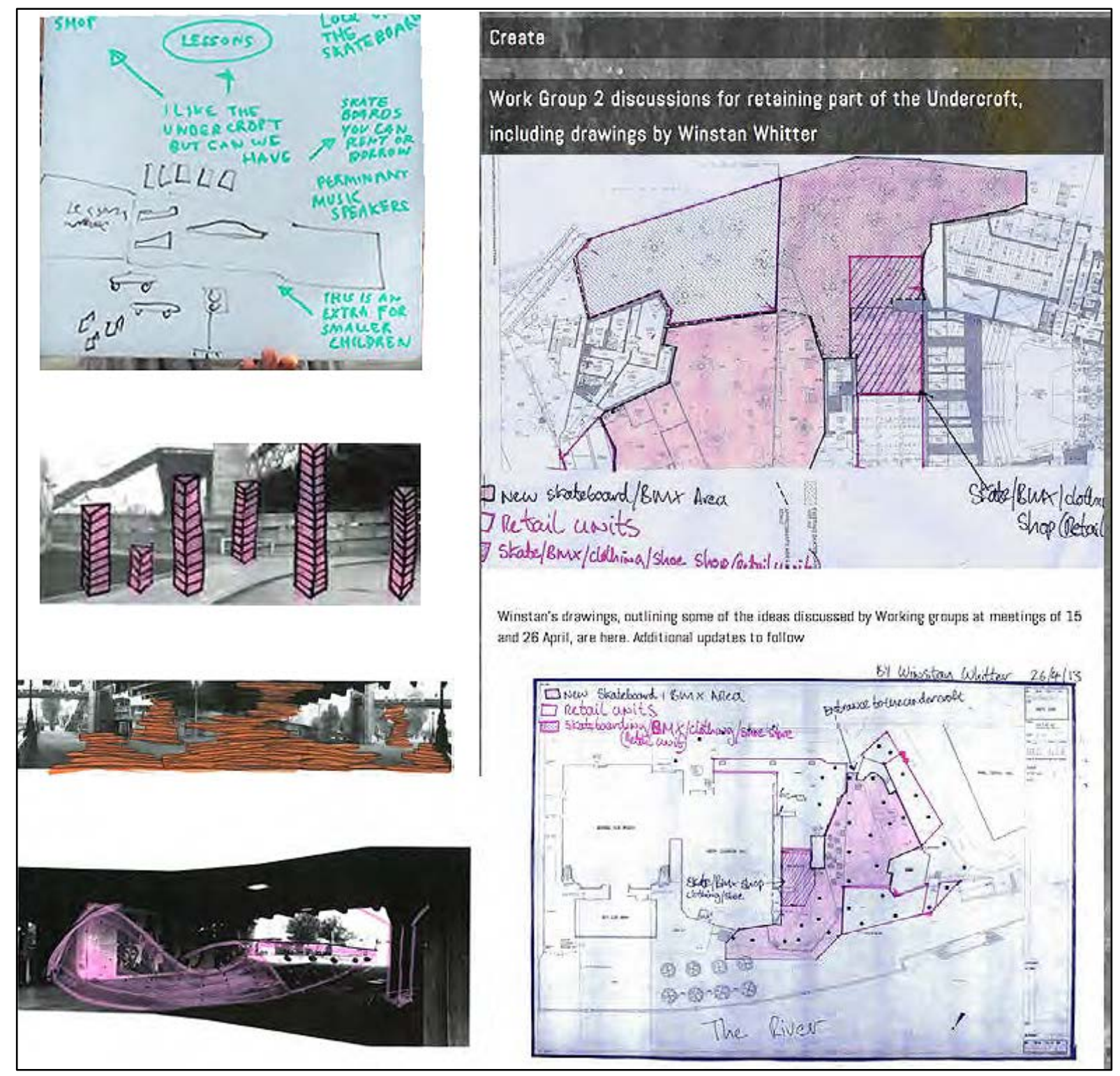

Fig. 4. Visual and spatial voices: sample ideas from those generated by individuals and working groups in the design-led engagement processes. Image: Southbank Undercroft codesign work groups and Socially Responsive Design \& Innovation, Central Saint Martins.

\section{CASE 3: Graffiti Dialogues Network}

Discourses around graffiti reveal many contradictory perspectives about desirable outcomes for 'better'. The Graffiti Dialogues Network (GDN) is included here as a possible example of a socially responsive movement towards 'critical urban planning', as Lopez de Souza (2006) and Gamman and Thorpe (2011) might frame it. Recent decades have seen technological developments but limited innovation in terms of inviting involved and affected voices, linked to graffiti. Rather, public and private resources are still invested based on assumptions over a narrow range of positions. This is part of the reason why GDN has been exploring some practice-led activities, to better understand viable alternatives to conflict in public space, building on approaches to graffiti and visual mark-making documented for example by Gómez (1993), Iveson (2010), Gamman and Willcocks (2011). 
The Graffiti Dialogues Network - designed as 'safe space' - was established between the Socially Responsive Design and Innovation unit, and Design Against Crime Research Centre at Central Saint Martins (UAL). It founded an unusually broad, sometimes opposing, spectrum of contributors: from local authorities and police, to representatives from guerrilla urbanism, transport, criminology, built environment, community safety, community activism, practice-led design, research, education and of course street artists and graffiti writers - each experts in their own experiences concerning the dialogues around graffiti.

GDN has facilitated new exchanges, in-field and desk-based research, interviews, designed workshops and events. Recent activities include the first known human graffiti library (December 2015) ${ }^{11}$ (fig. 6), development of an open galleries model (fig. 5) to be trialled in multiple locations, a three-day international public event, 'Graffiti Sessions' (London, December 2014), contributed to by international creators, promoters, preventers and managers of graffiti and street art ${ }^{12}$. Separately the GDN team has contributed as one of four partners to the European Graffolution project ${ }^{13}$.

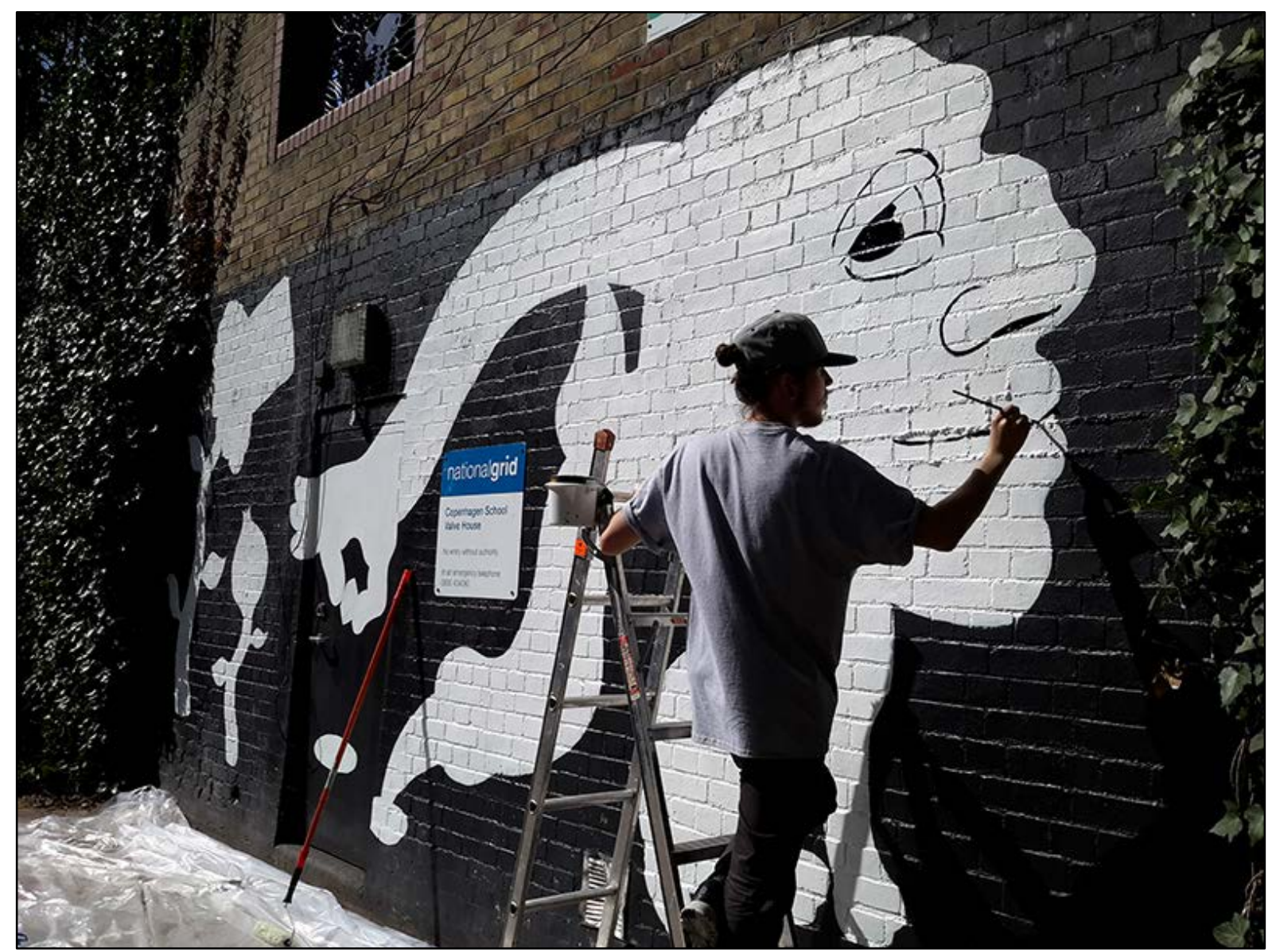

Fig. 5. One of the walls scheduled for one of the Open Galleries trials, inviting diverse publics to locate their visual voice on dedicated wall spaces, facilitated through an anonymous permissions system. Image: Leon Meredith 


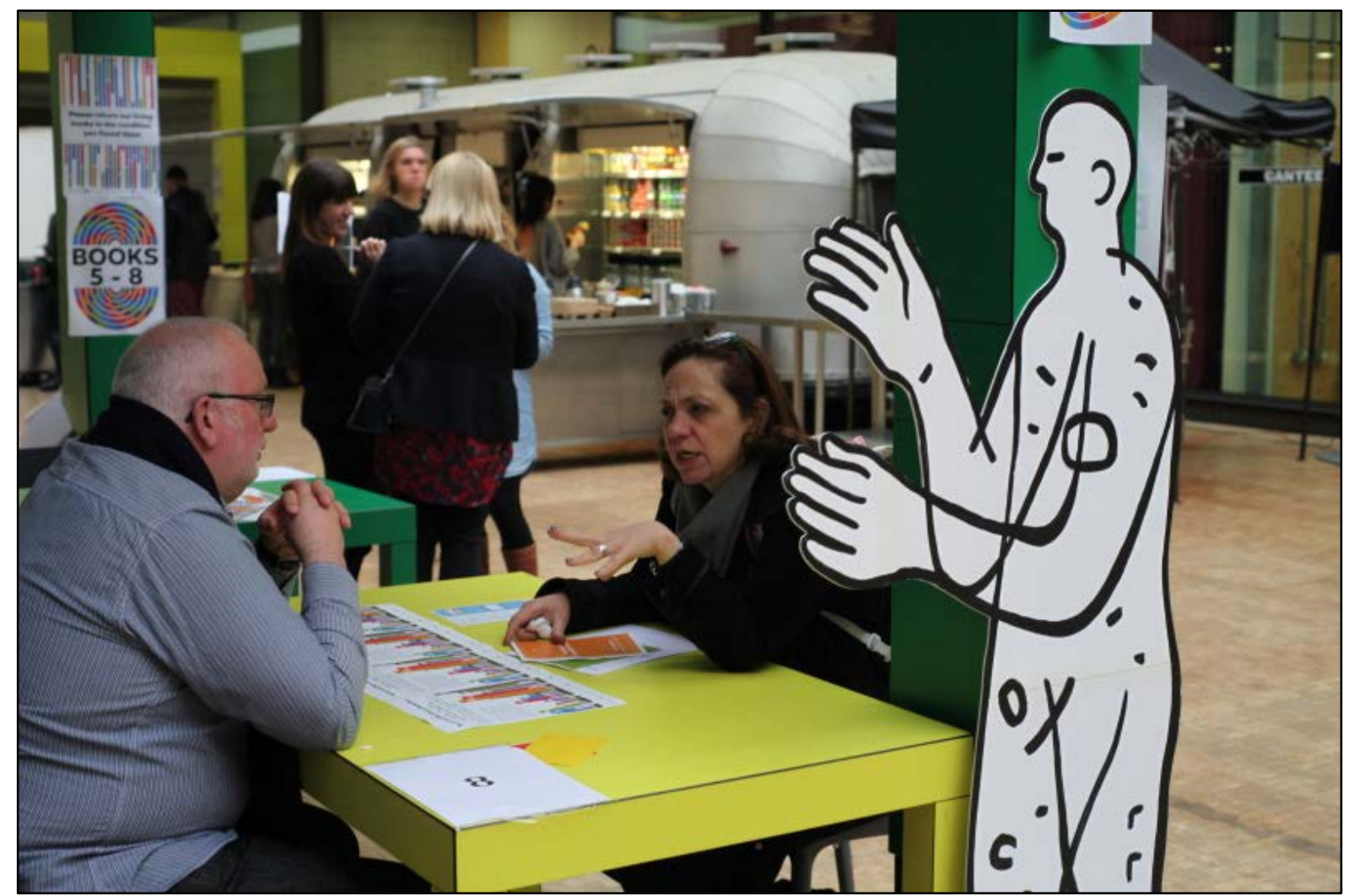

Fig. 6. Part of the first Human Graffiti Library, hosted at Central Saint Martins. Image: Design Against Crime Research Centre

Our 2014 review of over 300 sources for Graffolution found there are still two dominant views on graffiti ${ }^{14}$, for or against. Accounts from over 80 Graffoloution interviews, plus separate conversations, workshops and debates involving over 150 GDN contributors to date, suggest that many feel corralled into taking one of two oppositional roles, with little cultural, political or administered space for more nuanced or imaginative responses. For some the prime regime of value is protection of permissions over built property, or cleanliness, whilst for others it is about beauty, moral rights or other rights to the city (Soja, 2010, Slater, 2010). These conflicting regimes present as if victims of spatial injustices (Soja, 2010, Lefebvre, 1972), injustices inflicted through different understandings of symbolic violence being built into the city (Wacquant, 2012). While one workshop contributor describes, graffiti is 'selfish, it doesn't have permission, it's not fair on the 'others' in the city' ${ }^{15}$, an interviewee surmises, 'the system is selfish [...] why should we need permission to make public communication?' 16 . Through GDN activities, we hear graffiti writers and their networks-of-interest seeking to be taken more seriously in their claims to the city (Harvey, 2012). On paper, the tussle is disjointed and can never be resolved. In their own way however, graffitists have forged space as pioneers of Mouffe's vision, by using their practice to struggle with ideas of others without putting into question others' rights to defend those ideas.

GDN has identified a growing pool of exploratory and creative interventions - some institutionally-initiated, and some unsanctioned. What is common between them is that they are levering the possibilities further-open, regarding how to 'grant voice' visually or spatially, and who can 'get up' in cities (beyond only illegal writers, fee-paying developers, or advertisers). These interventions include for example: inviting artists to both paint and maintain previously-degraded walls in Brighton; combining inputs from service designers with commissioned graffiti artists, plus school-age children and community safety teams in the London Borough of Brent; and introducing an anonymous registration system in Barcelona ${ }^{17}$, that permits wider ranges of participants to have-a-go at painting spaces, affording reduced administration for authorities and increased 
participation and colour for locals. One argument for such actions is that they help progress both experimental, grass roots and DIY (Tonkiss, 2013) place-making, as well as municipal innovation. Sadly, the most interesting examples are still infrequent. For this kind of progression in place-making to proceed more widely, the GDN team observes another contestation that needs to mature first: one which addresses, why 'small-scale and auto-initiatives that embed quickly in place should be devalued' (Tonkiss, 2013, 313), and how institutionally-involved actions might be trusted sufficiently for suspicious publics to partake. The GDN related activities have started to evidence that more can and should be done across frontiers of interest-groups and disciplines, regarding what is valued, how, and for whom exactly. The GDN team is next seeking to test how we might more even-handedly evidence the benefits and pitfalls of such varied practices as those mentioned above, as part, we trust, of wider efforts and wrestles towards the next chapter of graffiti and urban creativity's places in unfinished cities (Chatterton, 2010).

\section{CONCLUSION}

The future of urban 'improvement' through design is perhaps looking less materiallyfocused than it used to. Even if full reflection on the above case studies cannot be delivered in this paper, I hope nevertheless to have reflected via the design-led examples given, that the tools and skills of design and design-led research can be of use in working towards contextually appropriate urban improvements. Such cases remind us that the value of design contributions, now and increasingly lies within processes which help facilitate and advance discourses between competing desirable agendas. This compares to the longer-standing roles of design in built environments, principally serving to materialise (make physical) and visualise the presence of different urban agendas.

The three short studies reviewed here also, I believe, identify some of the broadening roles and perspectives among designers and urban practitioners. Extensively-trained designers, place-makers and self-assigned urban interveners reflect evolving transdisciplinary and creative practices, often with more ephemeral and far-less 'photogenic' outcomes than the building or boulevard that city designers might have idolised in previous decades. As highlighted at the start of this article, the efforts of design in shared urban contexts are tricky, not least since they must inevitably serve a plurality of publics. In this sense, designers, city practitioners and community activists cannot easily achieve plural improvement for multiple publics through the generation of fixed urban forms long-predicated by planning and management processes. In fact, some of the struggles referred to above resulted where urban form delivered versions of exclusive improvement, beneficial only for particular publics. By contrast, the processes, engagements and material interventions associated to more agonistic design approaches, appear to enable wider mixes of publics to find space for their own and for collective actions (Manzini and Rizo, 2011, and Brand and Gaffikin, 2007).

\section{Ericson and Mazé suggest:}

'The public realm is the space where interests conflict, where diverse constituencies have a right to speak out and stake a claim. In the street, and other commons, questions for design include: whose purposes, forms and functions are represented. Which ideas or futures are embodied?' (Ericson and Mazé, 145, 2011)

In this respect, Gamman points out that the tools and 'wonky thinking' $(2008,137)$ of creative practitioners in urban contexts can help. She challenges design to now be pushed further. One way, for example, is to help open up chances for different and contesting publics to find their own balances of difference between themselves. Another is to invite people in more ways to have a go at hands-on with the city contexts they care about or are bothered by, to roll sleeves up and to do this enjoyably and imaginatively.

Robert Sampson reminds us that social structures established over time can help afford resilient negotiations, or at least some dependencies in space, that might improve crime 
rates and neighbourhood efficacy. He observes that social cohesion is demonstrated in contexts of 'trust with shared expectations' $(2001,2)$. However, some of the examples revealed through this paper might evidence more closely what Kurt Iveson and Manuel Delgado indicate to us, that there can be no single united or unitable public in urban contexts, rather there are 'public animals' each out for their own ends (Delgado, 1999), forming multiples of 'publics' (Iveson, 2007) across strands of common interest. It is here that we have seen that designed opportunities also seek to contribute in social space through creative practices or ephemeral interventions more akin to Montgomery's experiments.

The cases reviewed reflect growing tides in socially responsive approaches ${ }^{18}$ to the struggles of urban encounters, services, systems and more. The designs for these opportunities and transformations add process-led and practice-led forms (DESIS, 2015, Brand and Gaffikin, 2007, and Rust, Mottram \& Till, 2007) of contestation-through-doing, to Lopez de Souza's (2006) social action movements. Together it seems, these designed activities can have a significant bearing on mitigating mistrust or fear and on promoting social ties or urban wellbeing (each discussed by Sampson, 2012 and 1997, and Montgomery, 2013). We see that the product of a designed effort is not the only catalyst that matters, but the activity itself is vital, in affording workable, forward-looking contested spaces. While we may dream this could happen en-masse, examples such as those above, offer increasing glimpses of hands-on practice and urban creativity working away from built-in stalemate and towards dynamic, equitable and productive adversarial discourse.

\section{ENDNOTES}

${ }^{1}$ See Göbel (2013), plus the event program at http://www.heike-

delitz.de/Programm\%20Designed\%20to\%20improve.pdf [Accessed 02.12.2015]

2 Regarding topics debated during Designed to Improve workshop, 2014. The event discussed at length the use of design and building practices for improving 'social' urban contexts. Salingaros (2010) also discusses building social structure, and Amin (2007) reflects on the roles of the trans-local and non-human elements within the formation of 'urban social'.

${ }^{3}$ As discussed during Designed to Improve, 2014. In this paper we can take 'improvement' or 'better' to be understood as efforts towards positive urban evolutions, reflecting the greatest outcome(s) among diverse actors.

${ }^{4}$ See http://www.inefc.cat

${ }^{5}$ Sampson (2012) and Sampson, Raudenbush and Earls (1997) frame urban places with 'strong social ties' as those where there is willingness to intervene on behalf of the common good. Montgomery (2013) suggests that social ties are now the most important contributor to wellbeing and placemaking.

${ }^{6}$ INEFC defined sporting activities into traditional sports and games, modern sports and post-modern sports.

${ }^{7}$ Ecuavoley - Ecuadorian rules volleyball

8 The insights accrued by the CSM team were later reused by Southbank as content within the consultation legally required for the Festival Wing planning process. Ultimately the co-design team were replaced by a PR agency before the engagements finished, reflecting a change in priorities.

${ }^{9}$ See http://www.Ilsb.com

10 See for example

http://www.designcouncil.org.uk/sites/default/files/asset/document/ElevenLessons_Design_Council\%20(2).pdf and http://www.designagainstcrime.com/methodology-resources/design-methodology/\#users-abusers

${ }^{11}$ See http://www.designagainstcrime.com/2015/12/21/first-human-graffiti-library/

12 See http://graffitisessions.com/presentations

${ }^{13}$ See http://www.project.graffolution.eu

14 ibid

${ }^{15}$ Contribution from a crime prevention consultant during Graffiti Dialogues Workshops, February 2011, www.graffitidialogues.com.

${ }^{16}$ From interview with a graffiti writer, Graffiti Dialogues, May 2011.

${ }^{17}$ Described through presentations/case studies on www.graffitidialogues.com and www.graffitisessions.com

${ }^{18}$ Adopted for example by the DESIS network http://www.desis-network.org/content/codesign-volume-7-issue-

3-4-2011-special-issue-socially-responsive-design [Accessed 11.04.2015] 


\section{REFERENCES}

Amin, A. 2008. 'Collective culture and urban public space.' City. 12, 5-24.

Amin, A. 2007. 'Re-thinking the urban social.' City. 11, 100-114.

Bishop, C. 2006. 'The Social Turn: Collaboration and its Discontents.' Artforum, 44, 6, 178-183.

Ballaz, X. 2015. 'Barcelona: The Legal Turn'. In . Stavanger, Norway: NUART Festival. Accessed 14.06.2016 http://www.nuartfestival.no/nuartplus/program-2015/barcelona--the-legalturn.

Borden, I. 2001. Skateboarding, space and the city: architecture and the body. Oxford: Berg.

Brand, R., \& Gaffikin, F. 2007. 'Collaborative Planning in an Uncollaborative World.' Planning Theory, 6, 282-313.

Cavuşoğlu, E. \& Strutz, J. 2014. 'Producing force and consent: Urban transformation and corporatism in Turkey.' City, 18:2, 134148.

Chatterton, P. 2010. 'The urban impossible: A eulogy for the unfinished city.' City. 14, 234-244.

Churchman, C. W. 1967. 'Wicked Problems.' Management Science, 14, 4.

Crace, J 2013. 'Skating on the South Bank: my nights getting wrecked in the undercroft.' The Guardian, 29 July. London. Accessed 20.04.2014. http://www.theguardian.com/uknews/2013/jul/29/skating-south-bankskateboarding-undercroft

DESIS, 2015. 'University of the Arts London DESIS Lab.' DESIS Network. Accessed 04.04. 2015. http://www.desisnetwork.org/content/ual-university-artslondon-desis-lab

Delgado, M. 1999. El Ánimal Público: hacia una antropología de los espacios urbanos [The Public Animal: towards an anthropology of urban spaces]. Barcelona: Anagrama.

DiSalvo, C. 2012. Adversarial Design. Cambridge, Mass: MIT Press.

Ericson, M., \& Mazé, R. 2011. Design Act: socially and politically engaged design today: critical roles and emerging tactics. Stockholm: Iaspis.

Fisher, T., 2012. 'Design as Trickster.' In: Conference Proceedings, DRS 2012. Edited by Israsena, P., Tangsantikul, J., Durling, D. Chulalongkorn University, Bangkok: Design Research Society. 512-525. Accessed 21.12.2015 http://www.designresearchsociety.org/im ages/publications/2012drs/drs2012_vol2 .pdf

Fisher, T., \& Gamman, L. 2014. 'Good Things and Bad Things: Tricky objects, people and processes.' Paper and workshop at DRS 2014, Umea, June 15-19. (Unpublished)

Gamman, L. 2008. 'The Dark Side of Creativity in Cities?' Paper at What Makes Cities Creative? British Council, Warsaw. March 2008. March 16-18. Accessed 14.11.2015.

http://www.grippaclip.com/wpcontent/uploads/What-Makes-CitiesCreative_Warsaw_LG-New-Cover.pdf

Gamman, L. and Thorpe, A. 2012. 'Design For Agnostic Space - Reviewing Design Strategies For Conflict Accommodation in 'Wicked' Design Scenarios.' Paper at Cumulus conference, Helinski, May 2426. Accessed 18.04.2015.

http://cumulushelsinki2012.org/cumulush elsinki2012.org/wpcontent/uploads/2012/05/Design-ForAgnostic-Space.pdf

Gamman, L, \& Thorpe, A. 2011. Open innovation and participation in socially responsive art and design practice. Paper at CFP 4th World Conference on Design Research, 31 October - 4 November, Delft, Netherlands. (Unpublished)

Göbel, H. K. 2013. 'CFP: Designed to improve? Hamburg, May 22-24, 2014'. Arthist.net, November 27. Accessed 17.12.2015. http://arthist.net/archive/6499/view=pdf

Gómez, M. 1993. 'The Writing on Our Walls: Finding Solutions Through Distinguishing Graffiti Art From Graffiti Vandalism.' University of Michigan Journal of Law Reform, 263, 633-708.

Harvey, D. 2012. Rebel cities: from the right to the city to the urban revolution. New York: Verso.

Iveson, K. 2010. 'The wars on graffiti and the new military urbanism.' City. 14, 115134.

Iveson, K. 2007. Publics and the city. Malden, MA, Blackwell Pub.

Lopez De Souza, M. 2006. 'Social movements as 'critical urban planning' agents'. City. 10, 327-342.

Manzini, E \& Rizzo. 2011. 'Small Projects/Large Changes. Participatory Design as an Open Participated Process.' CoDesign, Vol 7, N 3-4. September 01. 
Mayer, M. 2013. 'First world urban activism.' City. 17, 5-19.

McAuliffe, C. 2014. 'The Significance of Graffiti and Street Art in the City of Sydney'. Paper at Graffiti Sessions, London. 4 December 2014. Accessed 22.11.2015. http://graffitisessions.com/presentations 2

Montgomery, C. 2013. Happy city: transforming

our lives through urban design. London, UK: Penguin.

Mouffe, C. 1999. 'Deliberative Democracy or Agonistic Pluralism?' Social Research 663: 745-758.

Pløger, J. 2004 'Strife: Urban Planning and Agonism.' Planning Theory 3 71, pp. 71 $-92$.

Puig Barata, N., Vilanova, A., Camino, X., Maza Gutierrez, G., Pasarello, M., Juan, D., \& Tarrago, R. E. 2006. 'Los espacios publicos urbanos y el deporte como generadores de redes sociales: el caso de la ciudad de Barcelona.' Apunts: Educación Física Y Deportes, 84, 76-87.

Reason, P., \& Bradbury, H. 2001. Handbook of action research: participative inquiry and practice. London, SAGE.

Rust, C., Mottram, J., \& Till, J. 2007. AHRC research review: practice-led research in art, design and architecture. Bristol: Arts and Humanities Research Council. Accessed 20.11.2015.

https://archive.org/details/ReviewOfPract ice-ledResearchInArtDesignArchitecture.

Salingaros, A. 2010. Caperna, M. Bauwens, D. Brain, A.M. Duany, M.W. Mehaffy, G. Mehta, et al. P2P Urbanism. San Antonio: University of Texas. Accessed 02.12.2015. http://zeta.math.utsa.edu/ yxk833/P2Pu rbanism.pdf

Sampson, R. J. 2012. Great American City: Chicago and the Enduring
Neighborhood Effect. Chicago:

University of Chicago Press.

Sampson, R. J., \& Raudenbush, S. W. 2001. Disorder in urban neighborhoods: does it lead to crime. Washington, D.C., U.S. Dept. of Justice, Office of Justice Programs, National Institute of Justice.

Sampson, R. J., Raudenbush, S. W. and Earls, F. 1997 'Neighborhoods and Violent Crime: A Multilevel Study of Collective Efficacy.' Science. 277, 918-924

Sands, S. 2014. 'Online, David Puts the Fear of God in Goliath', Evening Standard, 01 April, 15. London. Accessed 19.04.2014. http://www.standard.co.uk/comment/sar ah-sands-online-david-puts-the-fear-ofgod-in-goliath-9227620.html

Schafran, A. 2014. 'Debating urban studies in 23 steps'. City. 18, 321-330.

Slater, T. 2009. 'Missing Marcuse: On gentrification and displacement.' City. 13, 292-311.

Soja E. W. 2010. Seeking Spatial Justice. Minneapolis: University of Minnesota Press.

Tonkiss, F. 2013. 'Austerity urbanism and the makeshift city.' City. 17, 3, 312-324.

Wacquant, L. 2012. 'Pierre Bourdieu Comes to Town: Pertinence, Principles and Applications.' Keynote paper at 'Symbolic Power and Urban Inequality: Taking Bourdieu to Town', University of York, May 31 - June 01.

Willcocks, M., \& Gamman, L. 2011. 'Greening not cleaning graffiti walls'. Paper at Anti Graffiti Association Annual Conference. Islington, May 11-12. Accessed 22.11.2015. www.graffolution.eu/documents/graffoluti on/method/2/document_1.pdf

Willcocks, M. 2008. 'The Visual Codes Associated to Sport: an Interpretation of Public Space.' Apunts. 91 , 89-100.

Young, I. M. 1990. Justice and the politics of difference. Princeton, NJ: Princeton University Press.

Marcus Willcocks is a member of the Socially Responsive Design and Innovation Hub \& Design Against Crime Research Centre at Central Saint Martins, University of the Arts London, UK. Email: Marcus Willcocks m.willcocks@csm.arts.ac.uk 